
PENDUKUNG PENGAMBILAN KEPUTUSAN PENENTUAN PERALATAN PANCING

\author{
JURNAL \\ Diajukan Sebagai Salah Satu Syarat Mencapai Gelar \\ SARJANA KOMPUTER
}

Program Studi Sistem Informasi

STMIK Dharma Wacana Metro

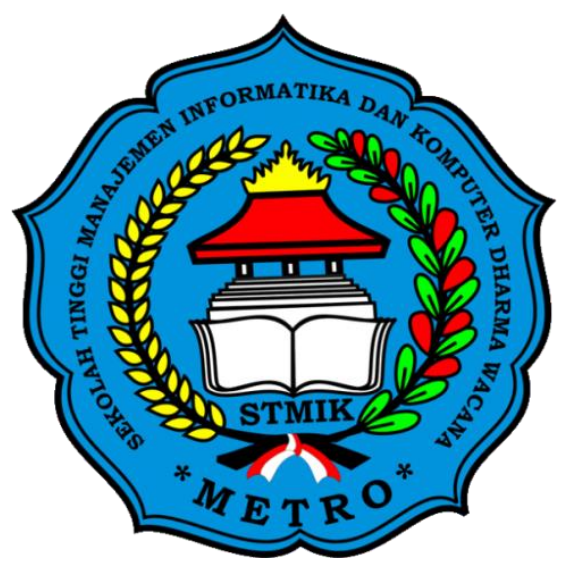

Disusun Oleh :

OKKE STEVANUS

16020010

PROGRAM STUDI SISTEM INFORMASI

SEKOLAH TINGGI MANAJEMEN INFORMATIKA DAN

KOMPUTER DHARMA WACANA METRO 


\title{
PENERAPAN METODE WEIGHT PRODUCT (WP) DALAM SISTEM PENDUKUNG PENGAMBILAN KEPUTUSAN PENENTUAN PERALATAN PANCING
}

\author{
Okke Stevanus $^{1}$, Tri Aristi Saputri², Usep Saprudin ${ }^{3}$ \\ ${ }^{1}$ Program Studi Sistem Informasi, STMIK Dharma Wacana Metro \\ ${ }^{2,3}$ Dosen Tetap Sistem Informasi, STMIK Dharma Wacana Metro \\ Jalan Kenangan No.3 Mulyojati Kota Metro \\ Email : s_okke@yahoo.com
}

\begin{abstract}
ABSTRAK
Memancing adalah kegiatan yang sejak zaman dahulu diminati oleh sebagian besar masyarakat indonesia, tidak hanya nelayan, tetapi orang awam kini yang menikmati akhir pekan untuk sekedar memancing. sebagian orang awam ketika akan melakukan memancing mengalami kesulitan dalam pemilihan piranti pancing. Penelitian ini bertujuan untuk para pemancing awam dalam menentukan pemilihan peralatan pancing. Manfaat dari penelitian ini adalah memberikan alternatif bagi pemancing awam dalam menghitung kebutuhan peralatan pancing yang akan digunakan, dengan kriteria kedalaman laut, arus laut, bobot ikan dan kelompok ikan. Pengembangan sistem ini menggunakan metode waterfall. Metode dalam sistem pendukung pengambilan keputusan, peneliti menggunakan metode weight product, metode ini merupakan penentuan sebuah keputusan dengan cara perkalian untuk menghubungkan rating atribut, dimana rating setiap atribut harus dipangkatkan dulu dengan bobot atribut yang bersangkutan, kemudian diterapkan kedalam sistem tersebut yang akan memberikan pilihan-pilihan peralatan pancing. Hasil yang dicapai, mampu melakukan perangkingan dari alternatif tersebut dan dapat digunakan oleh pemancing awam ketika akan melakukan aktifitas memancing, pada hasil perangkingan nilai tertinggi adalah piranti yang sangat disarankan.
\end{abstract}

Kata Kunci : weight product, sistem pendukung pengambilan keputusam, memancing

\section{PENDAHULUAN}

\section{Latar Belakang Masalah}

Di Indonesia hingga saat ini banyak masyarakat yang melakukan akhir pekan atau liburan untuk sekedar melakukan aktifitas memancing, Memancing merupakan salah satu hoby yang hingga kini digemari oleh sebagian besar masyarakat indonesia terbukti hingga saat kini banyak sekali komunitas-komunitas pemancing yang sifatnya berkelompok atau mancing bersama yang selalu mengadakan mancing bersama di sela-sela akhir pekan, sejak dulu memang memancing dijadikan aktifitas mata pencaharian, namun hingga saat kini, Memancing tidak hanya dijadikan mata pencarian saja, tetapi banyak orang awam yang mengikuti olahraga ini, untuk sekedar bersantai dan menghabiskan waktu di akhir pekan, untuk melakukan aktifitas memancing, Menurut ahira (2016) Secara luas, memancing merupakan kegiatan yang dilakukan menangkap sasarannya ikan, yang dilakukan di pinggir sungai, laut, danau dengan target seekor ikan.

Dalam memilih peralatan pancing hingga saat ini banyak sekali beredar jenis-jenis alat pancing mulai dari bermacam-macam merek joran, senar, rell pancing, mata pancing dan jenis-jenis umpan, yang mana tiap piranti tersebut memiliki ukuran-ukuran yang bisa disesuaikan.

Banyak pemancing awam atau pemula terkadang memiliki kendala saat akan melakukan aktifitas memancing, khususnya memancing di laut, untuk memancing di laut piranti yang digunakan harus bisa menyesuaikan dengan lingkungan laut yang ada, jika tidak bisa menyesuaikan ukuranukuran piranti yang ada maka tidak akan sesuai dengan harapan yang kita inginkan. Sementara itu piranti-piranti pancing tersebut dapat disesuaikan dengan kedalaman air laut, arus dasar laut, bobot ikan dan kelompok ikan.

Permasalahan pemilihan peralatan pancing dapat diselesaikan menggunakan sistem pendukung pengambilan keputusan (decision support system). Dalam sistem pendukung pengambilan keputusan, banyak metode yang dapat dipakai, salah satunya adalah metode Weight Product (WP). Menurut Dicky Nofriansyah (2014) Weight Product (WP) merupakan sebuah metode didalam penentuan sebuah keputusan dengan cara perkalian untuk menghubungkan rating atribut, dimana rating setiap atribut harus dipangkatkan dulu dengan bobot atribut yang 
bersangkutan. Proses ini sama halnya dengan proses normalisasi.

\section{Metode Weight Product (WP)}

Metode Weight product merupakan sebuah metode didalam menentukan sebuah keputusan dengan melakukan cara perkalian untuk menghubungkan rating atribut, lalu dimana setiap atribut harus dipangkatkan terlebih dahulu dengan bobot atribut yang berkaitan, proses ini sama halnya dengan normalisasi. Preferensi untuk alternatif Ai diberikan sebagai berikut :

$$
S i \prod_{j=1}^{n} X i j w j
$$

Keterangan :

S : Preferensi alternatif dianalogikan sebagai vector $\mathrm{S}$

\section{$X$ : Nilai Kriteria}

W : Bobot Kriteria atau sub kriteria

i : Alternatif (dimana $i=1,2, \ldots . . n$ )

$\mathrm{j}:$ Kriteria

$\mathrm{n}$ : Banyaknya kriteria

Sedangkan $\sum w j=1$ serta wj adalah pangkat bernilai positif untuk atribut keuntungan, dan bernilai negatif untuk atribut biaya.

$$
V i \frac{\prod_{j=1}^{n} X i j w j}{\prod_{j=1}^{n}(X j *) w j}
$$

Keterangan :

V : Preferensi alternativ dianalogikan sebagai vektor $\mathrm{V}$

\section{$X$ : Nilai Kriteria}

W : Bobot Kriteria atau sub kriteria

i : Alternatif

$\mathrm{j}:$ Kriteria

$\mathrm{n}$ : Banyaknya Kriteria

* : Banyaknya Kriteria yang telah dinilai pada vektor $\mathrm{S}$

Adapun langkah-langkah metode Weight Product :

1. Menentukan kriteria yang akan dijadikan acuan, $\mathrm{Ci}$
2. Menentukan rating kecocokan setiap alternatif pada setiap kriteria

3. Memperbaiki nilai bobot terlebih dahulu dengan cara membagi bobot dengan rata-rata bobot yaitu 100 dimana nilai 100 adalah jumlah persentasi kebutuhan

4. Nilai seluruh atribut kriteria dipangkatkan dengan bobot yang telah diperbaiki. Bagi sebuah alternatif dengan bobot pangkat positif untuk atribut manfaat dan bobot pangkat negatif pada atribut biaya

5. Seluruh nilai atribut kriteria dikalikan berdasarkan jumlah kriteria yang dimiliki setiap alternatif

6. Hasil perkalian dijumlahkan untuk menghasilkan nilai pada setiap alternatif

7. Mencari nilai hasil dengan melakukan pembagian dengan rata-rata dari nilai hasil setiap perkalian

8. Ditemukan urutan nilai hasil terbaik yang akan menjadi keputusan

\section{HASIL DAN PEMBAHASAN}

Kegiatan memilih peralatan pancing merupakan kegiatan yang dilakukan orang dalam melakukan memancing, namun memilih peralatan pancing yang tepat dan sesuai kebutuhan bukanlah hal mudah. Banyaknya pilihan peralatan pancing membuat pemancing awam bingung dalam memilih, oleh sebab itu peneliti akan membahas sistem pendukung pengambilan keputusan peralatan pancing yang sesuai dengan keinginan mereka. Dalam penelitian ini metode yang dipakai adalah weighted product. Berikut adalah tahapan metode weighted product :

\section{Menentukan Kriteria yang akan dijadikan acuan dalam pengambilan keputusan :}

Tabel 1 Kriteria

\begin{tabular}{|l|l|}
\hline \multicolumn{2}{|c|}{ Kriteria } \\
\hline C1 & $\begin{array}{l}\text { Kedalaman } \\
\text { Laut }\end{array}$ \\
\hline C2 & Arus Laut \\
\hline C3 & Bobot Ikan \\
\hline C4 & $\begin{array}{l}\text { Kelompok } \\
\text { Ikan }\end{array}$ \\
\hline
\end{tabular}

2. Menentukan rating kecocokan setiap alternatif pada setiap kriteria 
A. Alternatif A1 (Senar PE)

Tabel 2 Alternatif Senar PE

\begin{tabular}{|c|c|c|}
\hline Alternatif A1 & $\mathrm{C} 1$ & $\mathrm{C} 3$ \\
\hline 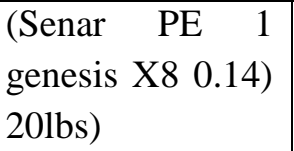 & 1 & 1 \\
\hline 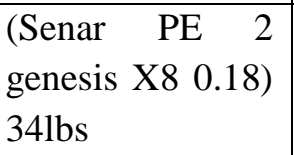 & 1 & 2 \\
\hline 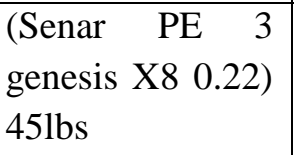 & 2 & 2 \\
\hline 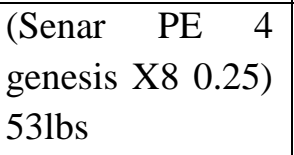 & 2 & 2 \\
\hline $\begin{array}{llr}\text { Senar } & \text { PE } & 5 \\
\text { genesis } & X 8 & 0.27) \\
67 l b s & & \end{array}$ & 3 & 3 \\
\hline 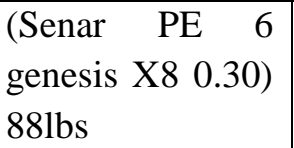 & 3 & 4 \\
\hline
\end{tabular}

B. Alternatif A2 (Mata Pancing)

Tabel 3 Alternatif mata pancing

\begin{tabular}{|c|c|c|}
\hline Alternatif A2 & C3 & $\mathrm{C} 4$ \\
\hline $\begin{array}{lr}\text { Mata } & \text { Pancing } \\
\text { Maguro } & \text { Premium } \\
\text { No.1 } & \end{array}$ & 1 & 1 \\
\hline $\begin{array}{lr}\text { Mata } & \text { Pancing } \\
\text { Maguro } & \text { Premium } \\
\text { No2 } & \end{array}$ & 1 & 1 \\
\hline $\begin{array}{lr}\text { Mata } & \text { Pancing } \\
\text { Maguro } & \text { Premium } \\
\text { No.3 } & \end{array}$ & 2 & 1 \\
\hline $\begin{array}{lr}\text { Mata } & \text { Pancing } \\
\text { Maguro } & \text { Premium } \\
\text { No.4 } & \end{array}$ & 2 & 1 \\
\hline $\begin{array}{lr}\text { Mata } & \text { Pancing } \\
\text { Maguro } & \text { Premium } \\
\text { No.5 } & \end{array}$ & 2 & 2 \\
\hline $\begin{array}{lr}\text { Mata } & \text { Pancing } \\
\text { Maguro } & \text { Premium } \\
\text { No.6 } & \end{array}$ & 3 & 2 \\
\hline $\begin{array}{lr}\text { Mata } & \text { Pancing } \\
\text { Maguro } & \text { Premium } \\
\text { No.7 } & \end{array}$ & 3 & 2 \\
\hline
\end{tabular}

\begin{tabular}{|c|c|c|c|}
\hline $\begin{array}{l}\text { Mata } \\
\text { Maguro } \\
\text { No. } 8\end{array}$ & $\begin{array}{l}\text { Pancing } \\
\text { Premium }\end{array}$ & 3 & 2 \\
\hline $\begin{array}{l}\text { Mata } \\
\text { Maguro } \\
\text { No.9 }\end{array}$ & $\begin{array}{l}\text { Pancing } \\
\text { Premium }\end{array}$ & 3 & 3 \\
\hline $\begin{array}{l}\text { Mata } \\
\text { Maguro } \\
\text { No. } 10\end{array}$ & $\begin{array}{l}\text { Pancing } \\
\text { Premium }\end{array}$ & 4 & 3 \\
\hline $\begin{array}{l}\text { Mata } \\
\text { Maguro } \\
\text { No.11 }\end{array}$ & $\begin{array}{l}\text { Pancing } \\
\text { Premium }\end{array}$ & 4 & 3 \\
\hline
\end{tabular}

C. Alternatif A3 (Timah J)

Tabel 4 Alternatif Timah J

\begin{tabular}{|c|c|c|}
\hline Alternatif A3 & $\mathrm{C} 2$ & $\mathrm{C} 1$ \\
\hline $\begin{array}{lr}\text { Timah } & \text { J.1 } \\
\text { sampai } & \text { dengan } \\
\text { J.4 } & \end{array}$ & 4 & 1 \\
\hline $\begin{array}{lr}\text { Timah } & \text { J.5 } \\
\text { sampai } & \text { dengan } \\
\text { J.6 } & \end{array}$ & 3 & 1 \\
\hline $\begin{array}{lr}\text { Timah } & \text { J.7 } \\
\text { sampai } & \text { dengan } \\
\text { J.9 } & \\
\end{array}$ & 3 & 2 \\
\hline $\begin{array}{lr}\text { Timah } & \text { J.10 } \\
\text { sampai } & \text { dengan } \\
\text { J.12 } & \end{array}$ & 2 & 3 \\
\hline
\end{tabular}

3. Memperbaiki nilai bobot terlebih dahulu dengan cara membagi bobot dengan ratarata bobot yaitu 100 dimana nilai 100 adalah jumlah persentasi kebutuhan

Berikut Studi kasus :

Kedalaman : 50 meter $(\mathrm{C} 1)$

Arus Laut : $8 \mathrm{~m} / \mathrm{d}(\mathrm{C} 2)$

Bobot Ikan : 35kilogram (C3)

Kelompok Ikan : plagis kecil (C4)

Nilai preferensi :

$\mathrm{W} 1: 2$

$\mathrm{W} 2: 3$

W3 $: 3$

W4 : 2 
Untuk mendapatkan hasil terlebih dahulu dilakukan perbaikan bobot, maka dapat perhitungan sebagai berikut dengan rumus

$$
\mathrm{Wj}=\frac{W j}{\sum w j}
$$
A. $\mathrm{W} 1=\frac{2}{2+3+3+2}=0.2(\mathrm{C} 1)$
B. $\mathrm{W} 2=\frac{3}{2+3+3+2}=0.3(\mathrm{C} 2)$
C. $\mathrm{W} 3=\frac{3}{2+3+3+2}=0.3(\mathrm{C} 3)$
D. $\mathrm{W} 4=\frac{2}{2+3+3+2}=0.2(\mathrm{C} 4)$

4. Nilai seluruh atribut kriteria dipangkatkan dengan bobot yang telah diperbaiki. Bagi sebuah alternatif dengan bobot pangkat positif untuk atribut manfaat dan bobot pangkat negatif pada atribut biaya Dan Seluruh nilai atribut kriteria dikalikan berdasarkan jumlah kriteria yang dimiliki setiap alternatif

A. Menghitung Vektor S, Senar PE dengan ${ }_{1}$

Kriteria C1 dan C3 :

1. $\mathrm{S} 1=1^{0.2} \mathrm{X} 1^{0.3}=1$

2. $\mathrm{S} 2=1^{0.2} \times 2^{0.3}=1.23$

3. $\mathrm{S} 3=2^{0.2} \times 2^{0.3}=1.41$

4. $\mathrm{S} 4=2^{0.2} \times 2^{0.3}=1.41$

5. $\mathrm{S} 5=3^{0.2} \times 3^{0.3}=1.73$

6. $\mathrm{S} 6=3^{0.2} \times 4^{0.3}=1.88$

B. Menghitung Vektor S, Mata Pancing dengan Kriteria C3 dan C4 :

1. $\mathrm{S} 1=1^{0.3} \times 1^{0.2}=1$

2. $\mathrm{S} 2=1^{0.3} \times 1^{0.2}=1$

3. $\mathrm{S} 3=2^{0.3} \times 1^{0.2}=1.23$

4. $\mathrm{S} 4=2^{0.3} \times 1^{0.2}=1.23$

5. $\mathrm{S} 5=2^{0.3} \times 2^{0.2}=1.41$

6. $\mathrm{S} 6=3^{0.3} \times 2^{0.2}=1.59$

7. $\mathrm{S} 7=3^{0.3} \times 2^{0.2}=1.59$

8. $\mathrm{S} 8=3^{0.3} \times 2^{0.2}=1.59$

9. $\mathrm{S} 9=3^{0.3} \times 3^{0.2}=1.73$

$10 . \mathrm{S} 10=4^{0.3} \times 3^{0.2}=1.88$

11.S11 $=4^{0.3} \times 3^{0.2}=1.88$

C. Menghitung Vektor S, Timah dengan Kriteria C2 dan C1

1. $\mathrm{S} 1=4^{0.2} \times 1^{0.3}=1.31$

2. $\mathrm{S} 2=3^{0.2} \times 1^{0.3}=1.24$

3. $\mathrm{S} 3=3^{0.2} \times 2^{0.3}=1.53$

4. $\mathrm{S} 4=2^{0.2} \times 3^{0.3}=1.59$

5. Hasil perkalian dijumlahkan untuk menghasilkan nilai pada setiap alternatif

A. Hasil Nilai Senar PE dengan Kriteria C1 dan C3 :
1. $\mathrm{S} 1=1$

2. $\mathrm{S} 2=1.23$

3. $\mathrm{S} 3=1.41$

4. $\mathrm{S} 4=1.41$

5. $\mathrm{S} 5=1.73$

6. $\mathrm{S} 6=1.88$

B. Hasil Nilai Mata Pancing dengan Kriteria $\mathrm{C} 3$ dan $\mathrm{C} 4$ :

1. $\mathrm{S} 1=1$

2. $\mathrm{S} 2=1$

3. $\mathrm{S} 3=1.23$

4. $\mathrm{S} 4=1.23$

5. $\mathrm{S} 5=1.41$

6. $\mathrm{S} 6=1.59$

7. $\mathrm{S} 7=1.59$

8. $\mathrm{S} 8=1.59$

9. $\mathrm{S} 9=1.73$

$10 . \mathrm{S} 10=1.88$

$11 . \mathrm{S} 11=1.88$

C. C. Hasil Nilai Timah dengan Kriteria C2 dan C1 :

1. $\mathrm{S} 1=1.31$

2. $\mathrm{S} 2=1.24$

3. $\mathrm{S} 3=1.53$

4. $\mathrm{S} 4=1.59$

6. Mencari nilai hasil dengan melakukan pembagian dengan rata-rata dari nilai hasil setiap perkalian

A. Menghitung Vektor V, Senar PE :

1. $\mathrm{V} 1=\frac{1}{8.66}=0.11$

2. $\mathrm{V} 2=\frac{1.23}{8.66}=0.14$

3. $\mathrm{V} 3=\frac{1.41}{8.66}=0.16$

4. $\mathrm{V} 4=\frac{1.41}{8.66}=0.16$

5. $\mathrm{V} 5=\frac{1.73}{8.66}=0.19$

6. $\mathrm{V} 6=\frac{1.88}{8.66}=0.21$

B. Mengitung Vektor V, Mata Pancing :

1. $\mathrm{V} 1=\frac{1}{16.13}=0.06$

2. $\mathrm{V} 2=\frac{1}{16.13}=0.06$

3. $\mathrm{V} 3=\frac{1.23}{16.13}=0.07$

4. $\mathrm{V} 4=\frac{1.23}{16.13}=0.07$

5. $\mathrm{V} 5=\frac{1.41}{16.13}=0.08$

6. $\mathrm{V} 6=\frac{1.59}{16.13}=0.09$

7. $\mathrm{V} 7=\frac{1.59}{16.13}=0.09$

8. $\mathrm{V} 8=\frac{1.59}{16.13}=0.09$

9. $\mathrm{V} 9=\frac{1.73}{16.13}=0.10$ 
$10 . \mathrm{V} 10=\frac{1.88}{16.13}=0.11$

$11 . \mathrm{V} 11=\frac{1.88}{16.13}=0.11$

C. Menghitung Vektor V, Timah :

1. $\mathrm{V} 1=\frac{1.31}{5.67}=0.23$

2. $\mathrm{V} 2=\frac{1.24}{5.67}=0.21$

3. $\mathrm{V} 3=\frac{1.53}{5.67}=0.26$

4. $\mathrm{V} 4=\frac{1.59}{5.67}=0.28$

\section{Ditemukan urutan nilai hasil terbaik} yang akan menjadi keputusan

A. Senar PE

1. (Senar PE 6 genesis $X 8$ 0.30) $88 \mathrm{lbs}) \mathrm{V} 6=0.21$

2. (Senar PE 5 genesis $\mathrm{X} 8$ 0.27) 67lbs) V5 $=0.19$

3. (Senar PE 4 genesis $\mathrm{X} 8$ 0.25) 53lbs) V4 $=0.16$

4. (Senar PE 3 genesis $X 8$ 0.22) 45lbs) V3 $=0.16$

5. (Senar PE 2 genesis $\mathrm{X} 80.18$ ) $34 \mathrm{lbs}$ V2 $=0.14$

6. (Senar PE 1 genesis X8 0.14) 20lbs ) V1 $=0.11$

B. Mata Pancing

1. (Mata Pancing Maguro Premium No.11) V11 = 0.11

2. (Mata Pancing Maguro Premium No.10) V10 $=0.11$

3. (Mata Pancing Maguro Premium No.9) V9 $=0.10$

4. (Mata Pancing Maguro Premium No.8) V8 $=0.09$

5. (Mata Pancing Maguro Premium No.7) V7 $=0.09$

6. (Mata Pancing Maguro Premium No.6) V6 $=0.09$

7. (Mata Pancing Maguro Premium No.5) V5 $=0.08$

8. (Mata Pancing Maguro Premium No.4) V4 $=0.07$

9. (Mata Pancing Maguro Premium No.3) V3 $=0.07$

10. (Mata Pancing Maguro Premium No.2) V2 $=0.06$

11. (Mata Pancing Maguro Premium No.1) V1 $=0.06$

C. Timah J

1. (Timah J.10 sampai dengan J.12) $\mathrm{V} 4=0.28$
2. (Timah J.7 sampai dengan J.9) $\mathrm{V} 3=0.26$

3. (Timah J.1 sampai dengan J.4)

$\mathrm{V} 1=0.23$

4. (Timah J.5 sampai dengan J.6) $\mathrm{V} 2=0.21$

\section{KESIMPULAN DAN SARAN}

\section{A. KESIMPULAN}

Berdasarkan hasil penelitian yang telah dilakukan, dapat disimpulkan sebagai berikut

1. Penerapan metode weight product ini memberikan hasil yang efisien, karena proses perhitungannya terbilang lebih singkat.

2. Penerapan metode weight product ini memberikan rekomendasi dalam pemilihan peralatan pancing untuk dijadikan bahan pertimbangan, tetapi keputusan akhir tetap kepada pengguna

B. SARAN

Berdasarkan kesimpulan diatas, maka terdapat beberapa saran yaitu sebagai berikut:

1. Selanjutnya diharapkan menggunakan metode lain sebagai pembanding hasil akhir.

\section{DAFTAR PUSTAKA}

1) Nofriansyah, D. (2014). Konsep data mining Vs Sistem pendukung keputusan. Yogyakarta: Cv budi utama.

2) Putra, G. M. (2014). Maskulinitas dan Praktik Tangkap Lepas dalam Memancing: Sebuah kajian terhadap Sportfishing.

3) P, Nugroho Pengaruh Perbedaan Ukuran Mata Pancing Terhadap Hasil Tangkapan Pancing Tonda diperairan Pelabuhanratu Sukabumi Jawa Barat. Skripsi Fakultas Perikanan Dan Ilmu Kelautan Institut Pertanian Bogor.

4) Dyna Marisa Khairina, D. I. (2016). Implementasi Metode Weighted Product Untuk Aplikasi Pemilihan Smartphone Android.

5) Anton chandra Setyawan (2016) Implementasi panduan persiapan mancing di laut (teknik popping,jigging, trolling, bottom fishing) berbasis web

6) Dyna Marisa Khairina, D. I. (2016).

Implementasi Metode Weighted Product Untuk Aplikasi Pemilihan 
Smartphone Android. ISSN : $2085-$

3688; e-ISSN : 2460-0997.

7) Yoga Handoko Agustin, H. K. (2015). Sistem pendukung keputusan penilaian kinerja dosen menggunakan metode weight product (studi kasus : STMIK PONTIANAK)

8) Dwi Cahyanto Yoni, H. M. (Mei 2016). Penerapan Metode WP (Weighted Product) Untuk Pemilihan Mahasiswa Lulusan Terbaik di Fakultas Teknik Universitas Muhammadiyah Purwokerto.

9) Fauzi, M. (2018). PENERAPAN METODE WEIGHT PRODUCT UNTUK SISTEM PENDUKUNG KEPUTUSAN PEMILIHAN PEMASOK ALAT MUSIK PADA STUDIO MUSIK ENTERPRISE. Jurnal Teknik Informatika Kaputama (JTIK) Vol. 2 , No. 1,.

10) Arman, Tri Aprianto Sundara,, Ilfa Stephane,, \& Muammar Fadli. (2019). Sistem Pendukung Keputusan Pemilihan Guru Terbaik dengan Metode Weighted Product pada MAN 1 PARIAMAN. JURNAL INFORMATIKA, Vol.6 No.2 ISSN: 2355-6579. 